\title{
JUSTICIA RESTAURATIVA: \\ UNA MIRADA A LAS NECESIDADES DE LA VÍCTIMA, LA PARTE OFENSORA Y LA COMUNIDAD
}

\author{
Restorative Justice: \\ A Look At The Needs Of \\ The Victim, The Offender Part And The Community
}

Mónica GONZÁLEZ TORRES*

No es la prolija aplicación de las leyes lo que sólo importa, sino el destino de víctimas y victimarios

Elías Neuman

Sumario:

I. El re-surgimiento de la justicia restaurativa II. Una aproximación teórica a la justicia restaurativa III. Las necesidades de las partes en la transformación del conflicto IV. Justicia restaurativa-retributiva ... ¿Es posible? V. La ética discursiva en Adela Cortina como base de la justicia restaurativa VI. Corolario

Resumen: La justicia restaurativa se centra más en la reparación y menos en el castigo, es una relectura en el tratamiento del delito, en el que éste se convierte en un conflicto, otorgándole a la víctima, la parte infractora y la comunidad de apoyo el protagonismo en la solución del conflicto. Mientras la víctima reivindica su papel dentro de la comunidad, la parte ofensora comprende las secuelas de su acción, asume su responsabilidad en la comisión del delito y se compromete a reparar los daños. Se trata de una justicia que abona a la pacificación social y propicia la recomposición del tejido social, en virtud de que todos estamos interconectados.Principio del formulario

* Licenciada en Derecho, con especialidad en Sistema Penal Acusatorio (énfasis en Mediación y Conciliación) y maestría en Derecho, en la línea de Derechos Humanos, ambas por la Universidad de Colima. Actualmente funge como titular del Centro de Estudios Judiciales del Supremo Tribunal de Justicia del Estado y profesora por horas en la Facultad de Derecho de la Universidad de Colima. Correo electrónico: mgtorres@ucol.mx. 
Palabras Clave: Restaurativa, Responsabilidad, Delito, Necesidades, Víctima, Comunidad, Diálogo

\begin{abstract}
Restorative justice focuses more on reparation and less on punishment, it is a rereading in the treatment of crime, in which it becomes a conflict, giving the victim, the offender and the support community the protagonism in the solution of the conflict. While the victim claims his role within the community, the offender understands the consequences of his action, assumes his responsibility in the commission of the crime and undertakes to repair the damage. It is a justice that pays social pacification and promotes the recomposition of the social connection, by virtue of which we are all interconnected.
\end{abstract}

Keywords: Restorative, Responsibility, Crime, Needs, Victim, Community, Dialogue

\title{
I. El re-surgimiento de la Justicia Restaurativa
}

La justicia restaurativa se propone como una relectura al tratamiento de los delitos y la violencia. Es una justicia que se centra más en la reparación que en el castigo; lejos de profundizar las heridas y agravar el conflicto, contribuye a la sanación y a la paz ${ }^{1}$. Bajo la perspectiva restaurativa, el delito daña a las personas y los lazos que se establecen en la colectividad, de modo que, quienes resultaron afectadas por un delito, son las que colaboran a fin de determinar el mejor camino para reparar el daño causado por el delito ${ }^{2}$.

$\mathrm{Si}$ bien sus antecedentes se encuentren en ciertas prácticas de justicia comunitaria realizadas por los grupos tribales e indígenas ubicados en América, África y Oceanía ${ }^{3}$, propiamente la justicia restaurativa resurgió en 1974, en Kitchener, Ontario, en Canadá, como una especie de reconciliación entre las víctimas y los ofensores.

El suceso que permitió ese resurgimiento contemporáneo fue el siguiente: dos jóvenes fueron acusados de vandalismo contra veintidós propiedades en una sola noche; la comunidad estaba indignada y los jóvenes no tenían antecedentes penales. Mark Yantzi, agente de libertad vigilada y responsable de preparar el proyecto de sentencia, consideró la viabilidad de que los jóvenes se reunieran con sus víctimas. En este sentido, Yantzi le sugirió al juez que además de la sentencia, los jóvenes asumieran plenamente su responsabilidad en la comisión de los hechos. En un principio, el juez rechazó la sugerencia por carecer de sustento legal; sin embargo, en el dictado de la sentencia la incorporó, con la condición de que el agente Yantzi rindiera un informe acerca de los

1 ZeHr, Howard \& GoHar, Ali (2003), The little book of restorative justice, Good Books, Pennsylvania, p. 2.

2 McCold, Paul y Wachtel, Ted (2003), En busca de un paradigma: una teoría sobre justicia restaurativa. Ponencia presentada en el XIII Congreso Mundial sobre Criminología, del 10 al 15 de agosto de 2003, en Río de Janeiro, Brasil, [en línea], disponible en: URL: https://goo.gl/2EY8zY, p. 1.

3 Veáse Neuman, Elías (2003), La mediación penal y la justicia restaurativa, Porrúa, México, pp. 1-3; WACHTEL, Ted (2013), Definiendo qué es restaurativo, [en línea], disponible en: URL: http://www.iirp.edu/ pdf/Defining-Restorative-Spanish.pdf, p. 2; BRITo RuIz, Diana (2010), Justicia restaurativa. Reflexiones sobre la experiencia de Colombia, Universidad Técnica Particular de Loja, Ecuador, p. 8; ZEHR \& GoHAR, op. cit. nota 1, p. 63. 
resultados. Fue entonces que los dos jóvenes acudieron con las víctimas, asumieron su responsabilidad, admitieron los daños ocasionados y acordaron la forma de repararlos, lo cual se logró en un plazo de tres meses ${ }^{4}$. Tras el éxito del caso, se estableció el primer programa de justicia restaurativa denominado Programa de Reconciliación Víctima y Ofensor (VORP). Entre 1977 y 1978 este programa se replicó -en pequeña escala- en Elkhart, Indiana, en Estados Unidos.

Como se puede advertir, los primeros pasos que se dieron respecto a los programas restaurativos, es que primero comenzaron con la práctica, y más tarde se abordó su conceptualización.

\section{Una aproximación teórica a la justicia restaurativa}

En aras de realizar una aproximación teórica de lo qué es la justicia restaurativa y no tergiversar la naturaleza y los alcances de ésta, resulta pertinente comenzar con la identificación de lo que no es restaurativo.

Al respecto, Zehr \& Gohar ${ }^{5}$ refieren que la justicia restaurativa no se enfoca exclusivamente en el perdón o la reconciliación; tratándose del otorgamiento del perdón, éste debe ser libre y genuino, de modo que ni la comunidad ni el proceso deben presionar para que la víctima lo otorgue ${ }^{6}$ Tampoco se circunscribe a un solo proceso restaurativo, lo relevante es advertir el proceso restaurativo que propiciará el diálogo y permitirá la exploración de posibilidades para resolver un conflicto. Tampoco se trata de un tipo de justicia diseñada específicamente para reducir la reincidencia o que se aborde en delitos no graves o con personas infractoras que lo son por primera vez. Se debe subrayar que la justicia restaurativa no es un sustituto del sistema legal ni tampoco resulta ser la panacea a los problemas que presentan la justicia penal ${ }^{7}$.

La justicia restaurativa parte de que el delito además de transgredir la norma es un conflicto interpersonal, y que éste es una oportunidad para transformar la situación en la que se encuentran las partes y evitar brotes de violencia. Lo anterior es así, porque el delito es una conducta que causa daño a la víctima y a la sociedad, de modo que la solución se busca estableciendo responsabilidades y obligaciones para la persona que delinquió, con miras al futuro, entre ellas la de reparar el daño para que la conducta delictiva no se repita.

$\mathrm{Si}$ bien es cierto se trata de una justicia focalizada en las necesidades de las víctimas, también lo es que considera las de la parte ofensora, ya que sigue siendo integrante de la sociedad. No se trata de eximirla de la responsabilidad en la comisión de delito y del compromiso en la reparación del daño; antes bien, es una justicia que se encamina a buscar la verdad y mantener la memoria como única posibilidad de dignificar a las víctimas, reintegrar al ofensor y brindar espacios para la transformación de la justicia ${ }^{8}$. Inclusive, al promover el diálogo y la asunción de responsabilidades por parte de la persona infractora,

\footnotetext{
4 Barros Leal (2015), César, Justicia restaurativa. Amanecer de una nueva era. Aplicación en prisiones y centros de internación de adolescentes infractores, Porrúa, México, pp. 4-5.

ZEHAR \& GoHAR, op. cit. nota 1, pp. 6-11.

Cfr. Barros, op. cit. nota 4, p. 183.

Ibidem, pp. 181-183.

Ibidem, p. 183.
} 
se procura la paz, sembrando así una cultura de prevención, en cuanto ya no se generan más delitos, y otra de reacción, encaminada a la restauración'.

Para esta aproximación teórica es preciso traer el paradigma de la justicia restaurativa desarrollado por McCold y Wachtel ${ }^{10}$, quienes lo abordan a partir de tres estructuras: a) ventana de la disciplina social, b) función de las partes interesadas, y c) tipología de la justicia restaurativa.

\subsection{Ventana de la disciplina social}

La teoría de la ventana de la disciplina social ${ }^{11}$ explica que las personas que desempeñan funciones que implican el ejercicio de autoridad tienen opciones para decidir las formas para mantener las normas sociales y los límites conductuales ${ }^{12}$. En este sentido, a través de la combinación de un mayor o menor apoyo (estímulos y enseñanzas) con un grado alto o bajo de control social (límites y disciplina) se generan cuatro enfoques ${ }^{13}$ que permiten atender la disciplina social. Si el apoyo es mayor existirá interés por el bienestar ${ }^{14}$, si es menor habrá desinterés por las necesidades físicas y emocionales ${ }^{15}$; respecto al control social, si éste es alto se impondrán límites y procurarán que se cumplan las normas establecidas, mientras que si es bajo se establecerán principios débiles y normas imprecisas.

Tratándose del enfoque restaurativo, es el más eficaz, pues a decir de los citados autores, la construcción del capital social y la disciplina social sólo se logra a través de una toma de decisiones responsable y un aprendizaje proactivo. En esta vertiente existe un genuino interés por el bienestar de la persona que delinquió, aun cuando le sean impuestos límites y se procure el cumplimiento de las normas que se han establecido para mantener el orden social. La participación de la comunidad, la reivindicación del rol de la víctima y, sobre todo, la reflexión de la persona ofensora acerca de los daños ocasionados y su correspondiente aceptación de la responsabilidad, son elementos considerados en la perspectiva restaurativa, e ignorados por los otros enfoques ${ }^{16}$.

${ }_{9}^{9}$ MARTIÑÓN CANO, Gilberto (2014), "La justicia restaurativa en materia penal como realización del principio de acceso a la justicia”, en: Mediación Penal y Justicia Restaurativa, Tirant Lo Blanch, México, p 51.

${ }^{10}$ McCold y Wachtel, op. cit. nota 2, p. 1.

${ }^{11}$ Ídem.

${ }^{12}$ Wachtel, op. cit. nota 3, p. 3.

${ }^{13}$ El enfoque punitivo o retributivo se caracteriza por estigmatizar a los infractores, en atención a que se les brinda un mínimo apoyo, pero existe un alto control social. Bajo esta vertiente, poco interesa si el ofensor reflexiona o participa activamente en la solución del problema, antes bien se responderá haciendo algo AL [sic] delincuente, amonestándolo y castigándolo. El enfoque permisivo o rehabilitativo surge con un bajo control social y un mayor apoyo, ya que se procura proteger a los infractores para que no sufran por las secuelas del delito, pues se hará todo POR [sic] el delincuente pidiendo poco a cambio y a menudo tratando de justificar el delito. El enfoque negligente se caracteriza por la indiferencia y la pasividad, por ello $N O$ [sic] se hará nada en respuesta a la conducta delictiva, ya que tanto el control social como el apoyo son nulos. El enfoque restaurativo o reintegrativo resulta de un alto control social y un mayor apoyo, pues le resta importancia a los delitos para enfatizar el valor intrínseco de los ofensores, al no señalarlos como delincuentes. Esta perspectiva se comprometerá $C O N$ [sic] el delincuente y otras personas procurando que: i) el infractor reflexione sobre sus actos y acepte su responsabilidad, y ii) las personas afectadas por el delito participen en el proceso de sanación. (Cfr. McCold y Watchel, op. cit. nota 2, p. 2).

${ }^{14}$ Ídem.

${ }^{15}$ Ídem.

${ }^{16}$ Por ejemplo, la perspectiva retributiva poco abona a la cohesión social, únicamente tiene interés en el 
Lo anterior implica que el camino restaurativo permite construir relaciones interpersonales basadas en la confianza, los valores, la comprensión y la cooperación ${ }^{17}$. Cuando las personas son involucradas en las decisiones que les afectan, sus puntos de vista escuchados y sus opiniones tomadas en cuenta de manera genuina, da como resultado la existencia condiciones para cooperar, ser más productivas y con ello generar cambios en sus conductas.

\subsection{Función de las partes}

Uno de los elementos torales en la justicia restaurativa es la colaboración de las partes en la búsqueda del mejor modo de reparar el daño que ha causado el delito; al respecto, McCold y Wachtel refieren que las partes interesadas pueden ser: i) primarias y ii) secundarias ${ }^{18}$. No obsta a lo anterior recalcar que la justicia restaurativa está más centrada en las necesidades de las partes interesadas primarias ${ }^{19}$, que son las víctimas, las ofensoras y sus respectivas comunidades de apoyo, que se conforman por quienes están vinculados afectivamente con estas partes. Para lograr una óptima reparación del daño es pertinente atender las distintas necesidades que presentan cada una de las partes primarias.

Como resultado del delito, la víctima ha perdido el control, por lo que necesita recuperarlo; por ello, entre sus necesidades se encuentran la reparación del daño, brindarle información real acerca del delito, permitirle contar la historia de lo sucedido a quienes le causaron daño, con miras a que comprendan el impacto de sus acciones; el empoderamiento, así como, la restitución y la reivindicación ${ }^{20}$.

La persona infractora es quien ha dañado las relaciones que tiene con su comunidad de apoyo y ha quebrantado la confianza, por lo que necesita asumir su responsabilidad en las consecuencias del delito. Comúnmente éstas no se sienten parte de la sociedad ${ }^{21}$, en vir-

reproche al infractor a través del castigo; de modo que existe un desinterés por las necesidades físicas o emocionales que pudiera tener el ofensor, además de que la víctima y la comunidad no participan en el proceso de solución, pues el Estado se encarga de la amonestación e imposición de límites, por lo que el infractor es estigmatizado. Por su parte, la vertiente permisiva se interesa por el bienestar del infractor, que sus necesidades físicas y emocionales sean atendidas; sin embargo, el establecimiento de normas y principios es débil e impreciso, de modo que el delito se justifica con otras circunstancias, sin que el infractor asuma su responsabilidad, ni tampoco sufra las consecuencias del delito. En tanto que, en el enfoque negligente no existe interés por el bienestar del infractor ni tampoco en el establecimiento de normas precisas, poco se abona a atender la conducta delictiva.

${ }^{17}$ Cfr. Wachtel y McCold (2004), "From restorative justice to restorative practices: expanding the paradigm". Paper from "Building a Global Alliance for Restorative Practices and Family Empowerment, Part 2," the IIRP's Fifth International Conference on Conferencing, Circles and other Restorative Practices, August 5-7, 2004, Vancouver, British Columbia, Canada, [en línea], disponible en: URL: https:/goo. gl/9WnjnP, p. 6.

${ }^{18}$ WaChTEL y MCCold, op. cit. nota 2, p. 2.

${ }^{19}$ Zehar \& Gohar, op. cit. nota 1, p. 16.

${ }^{20}$ Cfr. Ibidem, pp. 13-14.

${ }^{21}$ Por ejemplo, Catalina Pérez refiere que el individuo que cumple con una pena privativa de libertad previamente ya había sido excluido de la participación económica, social y/o política del país (Cfr. PÉREZ Correa, Catalina (2011), "De la Constitución a la prisión. Derechos fundamentales y sistema penitenciario", en: La reforma constitucional en Derechos Humanos: un nuevo paradigma, Serie Doctrina Jurídica 609, UNAM, México, p. 224. 
tud del proceso legal y la experiencia en la cárcel, lo que les desalienta a comprender las consecuencias de sus acciones o en su caso, tener empatía para con las víctimas ${ }^{22}$. En este sentido, necesitan que los daños sean abordados, a fin de fomentar la empatía y la responsabilidad, así como transformar la vergüenza; además de la inclusión de oportunidades para el tratamiento de adicciones u otros problemas, lo que implicaría el mejoramiento de las competencias personales y así fomentar su integración en la comunidad ${ }^{23}$.

Las comunidades de apoyo al ser los grupos cercanos -tanto a la víctima como a la parte ofensora- procuran la reconciliación ${ }^{24}$, ya que se encargan de coadyuvar de manera constructiva para evitar la reincidencia delictiva. $\mathrm{McCold}^{25}$ refiere que la sociedad desempeña un papel importante en la prevención de delitos y en la resolución de los conflictos; sin embargo, dicha responsabilidad ha sido evadida por la comunidad, al dejarla en manos de las autoridades e instituciones oficiales encargadas de juzgar a quien delinquió y asignarle un castigo, pensando que ahí concluirá dicha responsabilidad. Tampoco debe obviarse que el proceso de empoderamiento de la comunidad abona a la paz. Lo que las comunidades de apoyo necesitan de la justicia es que se les brinden oportunidades para construir un sentido de comunidad saludable, en la medida que se fomenta la asunción de obligaciones para el bienestar de sus integrantes, al tiempo que se promocionan las acciones preventivas ${ }^{26}$.

Como puede advertirse, la justicia restaurativa conserva sus raíces en la comunidad, como expresa de manera atinada Britto ${ }^{27}$, si los delitos y conflictos ocurren en la sociedad, por ende, sus consecuencias también, por lo que la búsqueda de soluciones también se encuentra en ellas. Es así que, con la participación de las partes interesadas primarias se abona a la recomposición del tejido social que se ha roto, pues la justicia restaurativa persigue como fines la obtención y el mantenimiento de la paz en la sociedad mediante el diálogo ${ }^{28}$.

El proceso de diálogo entre víctima - parte ofensora - comunidad debe realizarse por etapas, pues no es conveniente que el primer acercamiento sea entre quien resiente el daño y quien lo realizó. En un primer término debe buscarse el acercamiento entre las víctimas y la comunidad y posteriormente, deberá darse entre quien delinquió con la sociedad, para finalmente procurar el encuentro entre la víctima y la parte infractora. Lo anterior es así, porque el encuentro entre las víctimas y la comunidad otorga a las primeras la posibilidad de trascender su lugar de víctimas para que recuperen su dignidad, puedan ejercer sus derechos y sean capaces de transformar las situaciones de inequidad que las han puesto en el lugar de víctima ${ }^{29}$. Por su parte, la parte ofensora reconoce su responsabilidad y realiza "actos de reparación que le permitan re-situarse como persona y como ciudadano $(a)^{30}$. Finalmente, el encuentro entre quien resiente el daño y quien lo hizo ocurre

\footnotetext{
${ }^{22}$ Cfr. Zehr \& Gohar, op. cit. nota 1, pp. 14-15.

${ }^{23}$ Ibídem, p. 15.

${ }^{24}$ Wachtel, op. cit. nota 3.

${ }^{25}$ McCold, Paul (1995), Restorative Justice: the role of the community. Paper presented to the Academy of Criminal Justice Sciences Annual Conference, Boston, [en línea], disponible en: URL: http://www.iirp. edu/article detail.php?article id=NTA1.

${ }^{26}$ ZeHR \& GoHAR, op. cit. nota 1 , p. 16.

${ }^{27}$ BRITO, op. cit. nota 3, p. 19.

${ }^{28}$ Ibídem, p. 24.

${ }^{29}$ Ídem.

${ }^{30}$ Ídem.
} 
cuando la primera se ha fortalecido y la segunda se ha comprometido, de modo que la comunidad funge como un acompañante durante el proceso, además de ser un garante en la transformación de la violencia ${ }^{31}$.

Ahora bien, McCold y Wachtel ${ }^{32}$ en su paradigma sobre la justicia restaurativa también identifican a las partes interesadas secundarias, las cuales pertenecen comúnmente a las organizaciones educativas, religiosas, sociales o comerciales cuya área de responsabilidad o participación abarca el lugar o las personas afectadas por el incidente ${ }^{33}$. Esto implica que, el daño al ser indirecto y sus necesidades colectivas, apoyan al proceso restaurativo con la no interferencia en el proceso de pacificación y reconciliación, esto es, no retiran a las partes interesadas primarias el conflicto y con ello, la oportunidad de solucionarlo.

\subsection{Tipos y grados de prácticas de justicia restaurativa}

En la medida en que la víctima, la parte ofensora y la comunidad se involucren emocionalmente, procuren la solución del conflicto, participen en un proceso de pacificación y, sobre todo, sus necesidades queden satisfechas, se identificarán ciertos mecanismos como completa, mayoritaria o parcialmente restaurativos ${ }^{34}$, esto implica que la clasificación dependerá del grado de participación de las partes interesadas primarias.

Las prácticas serán parcialmente restaurativas cuando sólo participa una parte primaria, ya sea la víctima, la comunidad o la parte ofensora; como ejemplos destacan, según si atiende a la reparación del daño a la víctima: los servicios para las víctimas y el resarcimiento por el delito; si es para la identificación de la responsabilidad de quien delinquió, se encuentran los paneles de ayuda para jóvenes, los servicios comunitarios y las juntas de reparación; por su parte, si quienes requieren apoyo es la comunidad, destacan los acuerdos de comunidad de apoyo, tales como los servicios para las familias de las personas infractoras y la asistencia social para familias.

En las prácticas mayoritariamente restaurativas se involucran la víctima y la parte infractora, quedando excluidas las comunidades de apoyo; en esta categoría se identifican los círculos de apoyo para víctimas, la restitución de éstas, la mediación entre víctimas y parte ofensora, la disciplina positiva, las reuniones restaurativas sin las víctimas y las comunidades terapéuticas.

Este artículo se centra en las prácticas completamente restaurativas, ya que las partes interesadas primarias participan activamente; ejemplos de este tipo de prácticas, destacan los círculos de paz, las conferencias para grupos familiares y las reuniones restaurativas. Al respecto, el Manual de Naciones Unidas sobre Programas de Justicia Restaurativa ${ }^{35}$ menciona que un proceso completamente restaurativo alcanzará sus objetivos en la medida en que la víctima sea identificable y la persona que cometió un delito acepte su responsabilidad en la comisión y que ambas partes, participen de manera voluntaria.

\footnotetext{
31 Ídem.

${ }^{32}$ MCCold y Wachtel, op. cit., nota 2, p. 2.

${ }^{33}$ MCCOLD, op. cit., nota 25.

${ }^{34} C f r$. MCcold y Wachtel, op. cit., nota 2, p. 3.

${ }^{35}$ Oficina de las Naciones Unidas contra la Droga y el Delito (2006), Manual sobre programas de justicia restaurativa, Serie de Manuales sobre Justicia Penal, Naciones Unidas, Nueva York, pp. 7 y 8.
} 
La importancia de que exista voluntad en participar deriva de que, en los procesos restaurativos, al generarse un ambiente propicio para el diálogo, se asoman emociones, (re)sentimientos, disgustos, odio y compasión ${ }^{36}$, al tiempo en que se comienza a buscar el mejor camino para resolver el conflicto y atender los daños. Un aspecto relevante es que para implementar esos procesos restaurativos deben atenderse a los contextos sociales, pues como se ha referido, hay circunstancias que inciden en que la parte infractora comenta un delito, las cuales hay que identificar, al tiempo de conocer quienes participarán en la reparación del daño.

\section{Las necesidades de las partes en la transformación del conflicto}

A lo largo del texto se ha subrayado la atención que debe darse a las necesidades de las partes como un camino para proponer soluciones al conflicto en el cual se ven involucradas. Esto es así, porque la resolución restaurativa de un delito depende en gran medida de la atención brindada a los intereses y sobre todo, a las necesidades de las partes primarias. Es indispensable que quien cometió el delito asuma su responsabilidad y reconozca el daño ocasionado en la víctima y la comunidad; inclusive, ésta tiene que reconocer que existe una injusticia actualizada en la persona de la víctima.

Así también, para reconocer un avance en esta resolución restaurativa es pertinente que la víctima se sienta reparada; esto implica que la reparación a cargo de la parte ofensora podrá transitar desde cubrir una cierta cantidad en dinero, realizar ciertas actividades -ya sea a favor de la comunidad o de la propia víctima-, ofrecer disculpas hasta el compromiso de no volver a delinquir, en atención al sufrimiento ocasionado a la víctima. Justamente, uno de los aspectos no visibilizados en la justicia retributiva y que sí se atiende en la restaurativa tiene que ver con que la víctima siente que ha perdido el control de su vida, por ello tiene la necesidad de empoderarse.

Como se puede advertir, uno de los aspectos fundamentales de quien ha cometido un delito para que se advierta una resolución restaurativa es el compromiso de no volver a delinquir, ya que esa transformación resulta clave para el futuro, pues finalmente la intención de cambiar y hacer de su vida un proyecto constructivo no puede ser indiferente al conglomerado social; de modo que la comunidad también tiene un papel relevante en la construcción de ese proyecto de vida, y que en parte radica en abordar las causas que le motivaron a delinquir. De este modo, atender las necesidades de la víctima, la parte ofensora y la comunidad permite abonar al proceso de pacificación social y a la restauración de las relaciones interpersonales.

Para que las partes aborden sus necesidades, deben transitar de sus posiciones. Lo anterior es así porque si se enfrascan en éstas, realizan peticiones concretas, pero un tanto inflexibles y que sólo son benéficas para una de ellas, al tiempo que se utilizan dinámicas de comunicación agresiva por una de las partes y pasivas en las restantes, lo que no se encamina hacia lo restaurativo.

Los intereses son los objetivos que persiguen las multicitadas partes. En los encuentros restaurativos pueden ser satisfechos los intereses de una de las partes, ya sea que no se vean afectados los de quienes intervienen o que no sean atendidos. En tanto, las necesida-

${ }^{36}$ BARros, op. cit. nota 4, p. 26. 
des son el centro de los conflictos, atienden a la esencia del mismo y una vez exploradas, las partes cuentan con suficiente información para proponer soluciones. En este sentido es imprescindible que se generen condiciones para que la víctima, la parte ofensora y la comunidad se comuniquen de manera óptima, se sientan empoderadas y cooperen, a fin de encontrar acuerdos constructivos. Cuando las necesidades de la víctima son atendidas, su rol como tal es reivindicado; por ello es fundamental que recupere el control sobre su vida, le sea reparado el daño conforme a un abanico de posibilidades, cuente con información acerca del delito y sea empoderada. Un aspecto fundamental es que las víctimas en los encuentros restaurativos pueden contar la historia de lo sucedido a quienes les causaron daño, con miras a que comprendan el impacto de sus acciones; eso les permite alcanzar la paz mental y sentirse más seguras.

Bajo un enfoque restaurativo, la parte ofensora también tiene necesidades, aun cuando haya dañado las relaciones con su comunidad de apoyo y ha quebrantado su confianza. Para ello es indispensable que asuma su responsabilidad en las consecuencias del delito. Lo que necesitan es que la justicia propicie un encuentro que permita abordar los daños, fomentar la empatía y la responsabilidad. Cuando la parte ofensora asume la responsabilidad por los daños ocasionados, reflexiona sobre sus actos y repara el daño, se fomenta su integración en la comunidad.

Finalmente, la sociedad también tiene necesidades, ya que requiere que se le brinde oportunidades para construir un sentido de comunidad sano, lo cual se logrará en la medida en que se fomente la asunción de obligaciones para el bienestar de sus integrantes y se promuevan acciones preventivas. Justamente, el círculo más cercano a quien resiente el daño y quien lo ocasionó -familias y amistades- procura la reconciliación y coadyuva de manera constructiva para evitar la reincidencia delictiva. Sin embargo, la sociedad ha evadido su responsabilidad en la prevención de delitos y resolución de los conflictos, pues ha dejado en manos de autoridades e instituciones oficiales el juzgar y asignar un castigo a la parte ofensora, pensando que ahí concluye su responsabilidad. No se puede obviar que el proceso de empoderamiento de la comunidad abona a la pacificación social y que la justicia restaurativa conserva sus raíces en la sociedad; con relación a esto último cabe recordar que es en el ámbito social donde ocurren los delitos y conflictos, donde se resienten las consecuencias, pero también donde se encuentran las soluciones.

Ciertamente, atender las necesidades de las partes permite solucionar la situación conflictiva desde la raíz, porque a partir de ahí existen puntos en común que abonan a la construcción de acuerdos propositivos. Para que los procesos resulten integradores y restaurativos es indispensable que lejos de propiciar equidistancia entre agresor y agredido, entre víctima y victimario ${ }^{37}$ se generen condiciones para despojar a las partes de dichas etiquetas. Cuando en los procesos restaurativos se abordan las necesidades, lo que se procura es visibilizar que la parte ofensora, la víctima y la comunidad tratan de restañar sus heridas, restablecer su humanidad y la humanidad en las relaciones; las únicas categorías que concurren son la de quien reconoce el daño causado y la de quien reconoce sentirse destruido o anulado por el otro ${ }^{38}$.

\footnotetext{
${ }^{37}$ Ríos MARTín, Julián et. al (2011), "Reflexiones sobre la viabilidad de instrumentos de justicia restaurativa en delitos graves", en Justicia restaurativa, mediación penal y penitenciaria: un renovado impulso, Editorial Reus, Madrid, p. 134.

${ }^{38}$ Ídem.
} 
Un aspecto que debe subrayarse es que el abordaje de las necesidades no implica que en los procesos restaurativos se realicen transacciones, concesiones mutuas o negociaciones. Tratándose del perdón, éste es uno de los alcances de la justicia restaurativa, más no un elemento; pues depende en gran medida de las personas y del proceso experimentado durante los encuentros restaurativos: es una especie de sanación interna lo que propicia el perdón. Por ello -se subraya- los procesos restaurativos no se promueven para que las partes se perdonen, pues el perdón es algo personal y con ello, genuino; máxime que, permite alcanzar cierto grado de comprensión, no de justificación, del agresor (...). Tiene un carácter ético importante pues a través de él reconocemos en situaciones comprometidas la común condición humana y la dignidad de todas las personas ${ }^{39}$.

No debe obviarse que el delito repercute gravemente en la víctima y en la comunidad. Esto implica que la víctima alberga sentimientos de ira y humillación, los cuales el Estado canaliza en aras de evitar la venganza privada; en tanto, la comunidad siente quebrantada la confianza. Cuando la comunidad (tanto la de apoyo como la secundaria) participa en los procesos restaurativos coadyuva a que la parte infractora asuma su responsabilidad en los daños ocasionados, al tiempo que se le reconoce como integrante del conglomerado social, ya que aún cuando ha cometido un delito no deja de ser parte de la comunidad a la que pertenece. Pareciera que, en nuestros días, debido al daño ocasionado por la parte ofensora, ésta ya no forma parte de la sociedad, sino que es visibilizada como una persona que tiene que vivir al margen de quienes sí son respetuosos de la ley.

En comunidad, sus integrantes se vinculan, relacionan y cumplen con distintas funciones que permiten que el engrane comunitario funcione. Por ello, cuando la comunidad participa en los procesos restaurativos procura gestionar de modo responsable las consecuencias y los daños que el delito ha dejado en la víctima, la parte ofensora y también en ella misma, abonando así al proceso de pacificación social.

\section{Justicia restaurativa-retributiva ... ¿Es posible?}

La justicia restaurativa más allá de contraponerse a la retributiva, la complementa; inclusive puede lograrse un equilibrio entre ambas, pues es por demás sabido que la retributiva es insuficiente, ya que sólo se enfoca en el castigo y pierde de vista el papel de la víctima, nulifica la cooperación de la comunidad, pues procura la venganza y la imposición del castigo como un instrumento de control de la violencia, debido al miedo y el dolor generado por la delincuencia.

Lo anterior lo han identificado a través de preguntas, pues mientras la justicia retributiva se centra dar respuesta a: ¿Qué norma ha sido vulnerada? ¿Quién lo ha hecho? y ¿Qué castigo merecen quienes infringieron el orden?; la restaurativa se enfoca en ¿Quién fue dañado?, ¿Cuáles son las necesidades de quien recibió el daño? y ¿Quién tiene la obligación de satisfacer dichas necesidades? ${ }^{40}$.

Es de subrayarse lo que Britto puntualiza respecto a la justicia restaurativa, pues el he-

\footnotetext{
${ }^{39}$ Ibidem, p. 147.

${ }^{40}$ Cfr. Domingo, Virginia (2016), Un debate interesante: jjusticia restaurativa es igual que justicia transformadora?, [en línea], disponible en: URL: https://goo.gl/5N614, 4 de octubre.
} 
cho de que se centre más en la reparación que en el castigo, no significa que la imposición del castigo al ofensor sea equiparable a la reparación de la víctima ${ }^{41}$. Antes bien, como ha quedado señalado en retrolíneas, la víctima es parte fundamental en el proceso, por lo que se le brinda la oportunidad de superar el estigma del delito y reivindicar su lugar dentro de la sociedad, al tiempo que la parte ofensora asume la responsabilidad por los daños causados y la sociedad no se adjudica los costos de los daños.

En este sentido, resulta relevante no sólo atender a un tipo de justicia que sólo investigue los hechos e imponga penas, sino a una que atienda las necesidades de quien resiente el daño y de quien lo hace, a fin de abonar a la prevención del delito. Etxebarria ${ }^{42}$ refiere que, frente a la formalización del proceso penal, la justicia restaurativa tiende hacia una personalización de las partes, al permitir el diálogo entre las partes primarias interesadas, por lo cual el rol de la víctima se reivindica y con ello, su respeto y atención; además de que alienta la participación de la sociedad en la resolución del conflicto, particularmente el entorno más cercano.

Un aspecto más es que la justicia restaurativa, a diferencia de la retributiva, da pauta para atender todas las perspectivas que las partes necesitan para conocer la verdad, lo que no permite ésta, al dejar al margen algunos aspectos en el proceso penal que -en la restaurativa- resultan determinantes para solucionar el conflicto entre las partes. La justicia restaurativa es una respuesta mucho más enriquecedora y eficaz para abonar a la solución del conflicto que la pena propiamente. El proceso penal prescinde del diálogo, desvía el interés de las partes, encubre la verdad entre las diversas declaraciones y revictimiza a quien ha resentido el daño, mientras que los procesos restaurativos humanizan a las partes al permitir la comunicación.

Con relación a si la justicia restaurativa y retributiva pueden lograr un equilibrio, Zehr $\&$ Gohar $^{43}$ refieren que ese punto se logra en la medida en que la víctima merece algo y la parte infractora debe algo; de modo que, los enfoques abonan a la relación proporcional entre el hecho y la respuesta. En el caso Penal Miguel Castro Castro Vs. Perú, el juez Antônio Augusto Cançado Trindade -en su voto razonado- expone que la retributiva y la restaurativa se complementan. Esto es así, ya que existe una convergencia entre la búsqueda de la justicia mediante la sanción de los responsables por violaciones de los derechos humanos (la justicia retributiva) y la búsqueda de la rehabilitación de las víctimas de tales (la justicia restaurativa) ${ }^{44}$.

La Oficina de las Naciones Unidas contra la Droga y el Delito ha expuesto en el $M a-$ nual sobre Programas de Justicia Restaurativa que la justicia restaurativa persigue principalmente restaurar el orden y la paz de la comunidad, reparar las relaciones dañadas, denunciar el comportamiento delictivo como inaceptable y reafirmar los valores de la comunidad; dar apoyo a las víctimas y voz, permitir su participación, así como atender sus necesidades; motivar a todas las partes relacionadas para responsabilizarse, especial-

\footnotetext{
${ }^{41}$ Brito, op. cit., nota 3, p. 9.

${ }^{42}$ EtXebarria Zarrabeitia, Xabier (2011), "La justicia restaurativa y fines del derecho penal”, en: Justicia restaurativa, mediación penal y penitenciaria: un renovado impulso, Editorial Reus, Madrid, pp. 49-53.

${ }^{43}$ ZeHr \& GoHAR, op. cit. nota 1, pp. 59 y 60.

${ }^{44}$ Corte Interamericana de Derechos Humanos, voto razonado del juez Antônio Augusto Cançado Trindade en el Caso del penal Miguel Castro Castro Vs. Perú, sentencia del 2 de agosto de 2008, disponible en URL: http://www.corteidh.or.cr/docs/casos/articulos/seriec_181_esp.pdf, párrafo 97.
} 
mente a quienes delinquieron y prevenir la reincidencia motivando el cambio de la parte ofensora y facilitando su reintegración a la comunidad ${ }^{45}$. Es importante no perder de vista este último punto, ya que se le brinda la oportunidad de superar la etiqueta social de delincuente; lejos de restar, cuenta con la posibilidad de reinsertarse en la comunidad.

De lo expuesto se colige que la justicia restaurativa es una más humanizada, que viene a dar un respiro en cómo se percibe el delito y a quien delinquió, además del empoderamiento de la víctima y la comunidad; se trata de una relectura más humanizada del fenómeno delictivo y del actuar de la parte ofensora, además de respetuosa de los derechos humanos. Por ello resulta fundamental el cambio de cultura de quienes operan en el sistema de justicia penal, pues en ciertos momentos se ha percibido una deshumanización de las personas que las integran; (...) actitud [que] no les permite mirar a las personas que hay detrás de los usuarios del sistema, (víctimas y agresores) ${ }^{46}$.

Se ha mencionado que es una justicia que prioriza los derechos humanos, ya que considera que para reducir la violencia y sanar el tejido social dañado como consecuencia del delito ${ }^{47}$, la intervención del derecho penal debe ser mínimo; por ello, deben procurarse otros caminos que permitan superar la lógica del castigo pasando a una lectura relacional del fenómeno criminal, entendido primariamente como un conflicto que provoca la ruptura de expectativas sociales simbólicamente compartidas ${ }^{48}$.

Un aspecto que es dable subrayar es que, como McCold y Wachtel lo refieren, la justicia restaurativa no se aplica porque es merecida, sino porque es necesaria ${ }^{49}$. En la búsqueda de la solución al conflicto, primero se identifica la historia que existe detrás del conflicto, ya que las lesiones originadas por el delito generan la necesidad de ser reparadas y con ello la responsabilidad para asumir las consecuencias y satisfacer las necesidades ${ }^{50}$.

\section{La ética discursiva de Adela Cortina como base de la Justicia restaurativa}

La justicia restaurativa considera al delito como una representación de las relaciones interpersonales dañadas y como generadores de obligaciones, principalmente, la de corregir los errores ${ }^{51}$. Lo anterior se resalta en virtud de que todos estamos interconectados, por lo que el daño que se actualiza en una persona, también se le hace a los demás. En este sentido, la base ética de la justicia restaurativa es la vertiente discursiva o también llamada ética del consenso o ética de la otredad. Entre los exponentes de esta corriente se encuentran Otto Apel, Jürgen Habermas y Adela Cortina.

En el caso que nos ocupa, se abordará bajo las aportaciones de la autora, quien ha asentado las bases para construir lo colectivo, a partir de los mínimos morales y que las perso-

\footnotetext{
${ }^{45}$ Oficina de las Naciones Unidas, op. cit. nota 35, pp. 9-11, específicamente p.10.

${ }^{46}$ Flemming Tello, Nancy, "La justicia alternativa en el marco del sistema de justicia penal acusatorio", en: Revista Nuevo Sistema de Justicia Penal, 6, SEGOB, México septiembre del 2013, p. 5.

${ }^{47}$ Kala, Julio César, "Nuevos paradigmas del derecho penal a propósito de la justicia alternativa", en $\mathrm{Me}$ diación Penal y Justicia Restaurativa, Tirant Lo Blanch, México 2014, p. 201.

${ }^{48}$ Ibidem, p. 202.

${ }^{49}$ MCCOLD y WaChTel, op. cit. nota 2, p. 3.

${ }^{50}$ Cfr. MCCOLD, op. cit. nota 24.

${ }^{51}$ ZeHr \& GoHAR, op. cit. nota 1, pp. 17 y 18.
} 
nas al ser autónomas, responsables y solidarias pueden hacer un mundo justo y dichoso ${ }^{52}$. Esto es así porque una ciudadanía cordial resulta ser más activa en el mejoramiento de la sociedad, en la medida en que forma ciudadanos justos y activos, comprometidos en las distintas esferas de la sociedad civil ${ }^{53}$.

Las sociedades democráticas se caracterizan por tener un pluralismo moral, ya que así se comparten unos mínimos morales desde los que es posible construir juntos una sociedad más justa ${ }^{54}$ y unos máximos morales que cada persona procura entorno a la felicidad. Es preciso subrayar que Cortina acota el significado de pluralismo en una sociedad al referir que no todo vale, ya que a la sociedad no debe serle indiferente los actos de corrupción, la violación sistemática a los derechos humanos, la ausencia de reconocimiento de la dignidad de las personas y las injusticias cotidianas. Antes bien, esos mínimos que la ciudadanía ha consensado en compartir y establecer como base común, resultan pertinentes para la construcción de una sociedad más humanizada ${ }^{55}$.

Los mínimos morales son los derechos humanos, los valores guía y la actitud dialógi$\mathrm{ca}^{56}$; son mínimos porque existe un consenso sobre los cuales todas las personas están de acuerdo y que permiten lograr una auténtica convivencia, por ello están referidos a la justicia. De este modo, los mínimos morales son exigibles, ya que atienden a las necesidades y porque existe un consenso en el que se ha acordado como mínimo para lograr la justicia. Con relación a los valores guía, y dado que la sociedad es "axiológicamente pluralista", se hace imprescindible el consenso; es en sociedad donde se acuerdan los valores que deberán reconocerse para todos los integrantes del conglomerado social, teniendo como instrumento el diálogo y como límite el bien común. La actitud dialógica es otro de los mínimos morales, imprescindible para la resolución de conflictos; cuando el diálogo es utilizado propicia el reconocimiento de las demás personas, como seres autónomos, propiciando condiciones de tolerancia, preocupación activa, respeto y solidaridad ${ }^{57}$.

Como se puede advertir, el diálogo, los derechos humanos y los valores guía son elementos indispensables para llegar a acuerdos. Como lo señala Cortina, son esos mínimos de justicia por debajo de los cuales no se puede caer sin incurrir en inhumanidad ${ }^{58}$. Cada persona - por si sola- no puede descubrir qué es la justicia o qué es lo justo; para lograrlo necesita relacionarse, y eso es un reclamo de intersubjetividad ${ }^{59}$, sin pasar por alto que toda relación debe darse en un marco de respeto a los derechos humanos.

A partir de lo expuesto se colige que la justicia restaurativa conserva sus raíces en la comunidad, por lo que su base ética es la del consenso. Para la construcción de una sociedad más justa es necesaria la existencia de los mínimos morales ya mencionados, los cuales son compartidos por quienes integran la comunidad en virtud de haber alcanzado cierta conciencia social, la cual les permite combatir las injusticias cotidianas, así como

\footnotetext{
${ }^{52}$ Cortina, Adela (2000), La ética de la sociedad civil, $4^{\mathrm{a}}$ edición, Grupo Anaya, Madrid, p. 125.

${ }^{53}$ Ídem.

${ }^{54}$ Cortina, Adela (2010), Justicia cordial, Trotta, Madrid, p. 49.

${ }^{55}$ Cfr. Cortina, op. cit. nota 52, p. 103.

${ }^{56}$ Cfr. Beuchot, Mauricio (2011), Derechos Humanos: Historia y Filosofía, 5ta. edición, Fontamara, México, p. 27.

${ }^{57}$ Cfr. Cortina, Adela (2014), ¿Para qué sirve realmente...? La ética, $3^{\text {a }}$ edición, Paidós, España, pp. 115-116.

${ }^{58}$ Ibídem, p. 155.

${ }^{59}$ Ibídem, pp. 155 y 156.
} 
exigir el reconocimiento a los derechos humanos y la dignidad. Es por ello que para identificar la justicia es indispensable la alteridad, por lo que se reconoce la importancia del diálogo y se enfatiza la cooperación en aquello que resulta común en aras de mejorar la sociedad, porque así se genera capital social, siempre en un marco de ejercicio de la libertad y de respeto a los derechos humanos.

\section{Corolario}

La justicia restaurativa conserva sus raíces en la comunidad y resulta que el delito, los conflictos, las consecuencias y las soluciones también se encuentran ahí. La base ética sobre la cual se construye la justicia restaurativa es la vertiente del consenso, también conocida como la discursiva o de la otredad, en virtud de que esta corriente parte de la intersubjetividad, esto es, del reconocimiento al otro. Este tipo de justicia -la restaurativase encamina hacia la paz y procura que se resuelva el conflicto, se conozca la verdad, se dé el arrepentimiento y la asunción de la responsabilidad, así como que se recomponga el tejido social en virtud de que todos estamos interconectados.

La comisión de un delito resulta un daño hacia las personas y la comunidad, y con ello, una ruptura del tejido social, por lo que es necesario sanarlo y atender a los procesos de pacificación. Cuando el delito es visibilizado como un conflicto, la reparación del daño -tanto material como simbólica- se convierte en un pilar, al tiempo en que reivindica el papel de la víctima en la comunidad de la que forma parte. Para la justicia restaurativa, poco le interesa el castigo a quien cometió el delito, antes bien enfatiza su responsabilidad, enfocándose en que la parte ofensora comprenda las consecuencias de su comportamiento. Lo anterior se logra porque se da respuesta a lo siguiente: i) ¿quién ha sido herido?, ii) ¿cuáles son sus necesidades?, iii) ¿cuáles son las obligaciones?, iv) ¿por qué ha ocurrido?, v) ¿quién tiene interés en la situación?, vi) ¿cuál es el proceso idóneo para que las partes interesadas se involucren, el conflicto se solucione y la situación no se repita? ${ }^{60}$.

Howard Zehr, considerado como el padre de la justicia restaurativa, señala que la manera de ver el delito puede identificarse a través de unos lentes. Un cristal será el lado retributivo, el cual examina al delito como una violación hecha contra el Estado, por lo que debe imponérsele dolor a quien delinquió; el otro cristal tiene un enfoque restaurativo, por lo que el delito se visualiza como una ofensa que se da entre las personas por lo que es necesario que el daño sea reparado para que las relaciones se restauren. Más allá de la imposición de un castigo como instrumento de control de la violencia -como en la retributiva-, habrá que ver que en la restaurativa se generan las condiciones para la cooperación de la comunidad y la solución de conflictos. La resolución restaurativa de un delito depende en gran medida de la atención que se le brinden a las necesidades de la víctima, la parte ofensora y la comunidad.

\section{Fuentes consultadas}

Barros Leal, César (2015), Justicia restaurativa. Amanecer de una nueva era. Aplicación en prisiones y centros de internación de adolescentes infractores, Porrúa, México.

${ }^{60}$ ZeHR \& GoHAR, op. cit. nota 1, pp. 20 y 41. 
Beuchot, Mauricio (2011), Derechos Humanos: Historia y Filosofía, 5ta. edición, Fontamara, México.

Brito RuIz, Diana (2010), Justicia restaurativa. Reflexiones sobre la experiencia de Colombia, Universidad Técnica Particular de Loja, Ecuador.

Corte Interamericana de Derechos Humanos, voto razonado del juez Antônio Augusto Cançado Trindade en el Caso del penal Miguel Castro Castro Vs. Perú, sentencia del 2 de agosto de 2008, [en línea], disponible en: URL: https://goo.gl/ymHhKY.

Cortina, Adela (2014), ¿Para qué sirve realmente...? La ética, $3^{\text {a }}$ edición, Paidós, España. (2010), Justicia cordial, Trotta, Madrid.

(2000), La ética de la sociedad civil, $4^{\mathrm{a}}$ edición, Grupo Anaya, Madrid.

Domingo, Virginia (2016), Un debate interesante: ¿justicia restaurativa es igual que justicia transformadora?, disponible en URL: https://goo.gl/5N614, 4 de octubre.

EtXebarria Zarrabeitia, Xabier (2011), "La justicia restaurativa y fines del derecho penal", en Justicia restaurativa, mediación penal y penitenciaria: un renovado impulso, Editorial Reus, Madrid.

Flemming Tello (2013), Nancy, "La justicia alternativa en el marco del sistema de justicia penal acusatorio", en: Revista Nuevo Sistema de Justicia Penal, 6, SEGOB, México septiembre.

Kala, Julio César (2014), "Nuevos paradigmas del derecho penal a propósito de la justicia alternativa", en: Mediación Penal y Justicia Restaurativa, Tirant Lo Blanch, México.

MARTIÑón CANO, Gilberto (2014), "La justicia restaurativa en materia penal como realización del principio de acceso a la justicia”, en: Mediación Penal y Justicia Restaurativa, Tirant Lo Blanch, México.

MCCold, Paul (1995), Restorative Justice: the role of the community. Paper presented to the Academy of Criminal Justice Sciences Annual Conference, Boston, disponible en URL: http://www.iirp.edu/article_detail.php?article_id=NTA1.

y Wachtel, Ted (2003), En busca de un paradigma: una teoría sobre justicia restaurativa. Ponencia presentada en el XIII Congreso Mundial sobre Criminología, del 10 al 15 de agosto de 2003, en Río de Janeiro, Brasil, disponible en URL: https://goo.gl/2EY8zY.

Neuman, Elías (2003), La mediación penal y la justicia restaurativa, Porrúa, México.

Oficina de las Naciones Unidas contra la Droga y el Delito (2006), Manual sobre programas de justicia restaurativa, Serie de Manuales sobre Justicia Penal, Naciones Unidas, Nueva York.

Pérez Correa, Catalina (2011), "De la Constitución a la prisión. Derechos fundamentales y sistema penitenciario", en: La reforma constitucional en Derechos Humanos: un nuevo paradigma, Serie Doctrina Jurídica, 609, UNAM, México.

Ríos MarTín, Julián et. al (2011), "Reflexiones sobre la viabilidad de instrumentos de justicia restaurativa en delitos graves" en: Justicia restaurativa, mediación penal y penitenciaria: un renovado impulso, Editorial Reus, Madrid. 
Wachtel, Ted (2013), Definiendo qué es restaurativo, [en línea], disponible en: URL: https://goo.gl/88kWgP

y MCCold, Paul (2004), From restorative justice to restorative practices: expanding the paradigm. Paper from "Building a Global Alliance for Restorative Practices and Family Empowerment, Part 2," the IIRP's Fifth International Conference on Conferencing, Circles and other Restorative Practices, August 5-7, 2004, Vancouver, British Columbia, Canada, [en línea], disponible en: URL: https://goo. gl/9WnjnP

ZeHr, Howard \& GoHar (2003), Ali, The little book of restorative justice, Good Books, Pennsylvania. 